\title{
WEBSITES EM BIBLIOTECAS UNIVERSITÁRIAS COMO INSTRUMENTOS PARA A FORMAÇÃO DE COMPETÊNCIAS EM INFORMAÇÃO
}

\author{
WEBSITES IN ACADEMIC LIBRARIES AS TOOLS FOR INFORMATION LITERACY \\ SITIOS EN BIBLIOTECAS UNIVERSITARIAS COMO INSTRUMENTOS PARA LA \\ FORMACIÓN DE ALFABETIZACIÓN INFORMACIONAL
}

${ }^{1}$ Marcos Aurélio Gomes, ${ }^{2}$ Lígia Maria Moreira Dumont

${ }^{1}$ Universidade Federal de Alagoas, ${ }^{2}$ Universidade Federal de Minas Gerais

\section{Correspondência}

${ }^{1}$ Marcos Aurelio Gomes

Universidade Federal de Alagoas

Maceió, AL - Brasil.

Email: marcosaureliog@gmail.com

ORCID: http://orcid.org/0000-0002-7803-5145

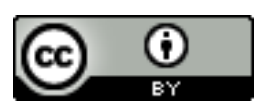

JITA: DD. Academic libraries 
RESUMO: Objetiva identificar nos websites das bibliotecas universitárias a prática da educação/formação de usuários por meio de produtos e serviços que podem ser fomentados tanto em ambientes tradicionais como digitais/virtuais na perspectiva da promoção de competências em informação dos estudantes. Pesquisa classificada como exploratória, estabeleceu em seu desenho como recorte duas universidades: a Universidade Federal de Alagoas e a Universidade Federal de Minas Gerais. A análise dos dados foi realizada com enfoque quantitativo e qualitativo. Adotou-se como instrumento de coleta o formulário, que proporcionou o levantamento de dados em 35 bibliotecas das duas instituições. Os resultados forneceram evidências de que as bibliotecas das duas universidades encontram-se em processos de transição ao se considerar o ponto de vista de uso da tecnologia digital para a potencializar as ações de educação/formação de usuário para desenvolver a competência em informação.

PALAVRAS-ChAVE: Biblioteca universitária. Competência em informação. Educação em biblioteconomia.

Página Web.

ABSTRACT: It aims to identify on the websites of university libraries the practice of education of users through products and services that can be fostered in both traditional and digital/virtual environments with a view to promoting students' information literacy. Research classified as exploratory, established in its drawing two universities: the Universidade Federal de Alagoas and the Universidade Federal de Minas Gerais. Data analysis was performed with a quantitative and qualitative approach. It was adopted as a collection instrument the form, which provided the data collection in 35 libraries of the two institutions. The results provided evidence that the libraries of the two universities are in transition processes when considering the use of digital technology viewpoint to enhance user' education actions to develop information literacy.

KEYWORDS: Academic libraries. Information user instruction. Information literacy. Web Sites.

RESUMEN: Objetivo identificar en los sitios web de las bibliotecas universitarias la práctica de la educación/formación de usuarios a través de productos y servicios que pueden ser fomentados tanto en ambientes tradicionales como digitales/virtuales en la perspectiva de la promoción de competencias en información de los estudiantes. La investigación clasificada como exploratoria, estableció en su diseño como recorte dos universidades: la Universidade Federal de Alagoas y la Universidade Federal de Minas Gerais. El análisis de los datos fue realizado con enfoque cuantitativo y cualitativo. Se adoptó como instrumento de recolección el formulario, que proporcionó el levantamiento de datos en 35 bibliotecas de las dos instituciones. Los resultados proporcionaron evidencias de que las bibliotecas de las dos universidades se encuentran en procesos de transición al considerar el punto de vista de uso de la tecnología digital para la potenciar las acciones de educación/formación de usuario para desarrollar la competencia en información.

PALABRAS CLAVE: Biblioteca acadêmica. Formación de usuarios de información. Alfabetización informacional. Paginas Web. 


\section{INTRODUÇÃ̃o}

A competência em informação representa na contemporaneidade as habilidades, os conhecimentos e a compreensão dos indivíduos em relação ao processo de busca, acesso, uso e comunicação da informação de forma ética a partir de necessidades também vinculadas à informação. A dimensão da competência associada à informação não se restringe aos profissionais da informação, mas sim se estende para todos os indivíduos que a utilizam na tomada de decisões simples ou complexas, independentemente dos espaços de sua atuação na sociedade. Ainda assim, tal competência torna-se "[...] temática promissora que poderá dar visibilidade às ações dos profissionais e pesquisadores da área de informação." (LEITE, et al, 2016, p. 152). Provavelmente, por meio dessa visibilidade é que as bibliotecas, notadamente as escolares e universitárias, podem tornar-se protagonistas no desenvolvimento da competência em informação. Belluzzo e Feres (2015) as consideram como centros de recursos e partícipes do processo de ensino-aprendizagem, por conseguinte tornam-se responsáveis tanto pela promoção quanto pelo desenvolvimento de tal competência.

No cenário nacional tudo indica que as bibliotecas universitárias possuem, muito em função da precária presença das bibliotecas escolares no país, maior responsabilidade em planejar instrumentos que potencializem a formação dos usuários em relação aos recursos informacionais para além dos espaços e acervo da biblioteca (GOMES, 2016). Assim, tornase necessário um novo olhar para suas práticas. Ao considerar esta perspectiva para as bibliotecas universitárias, os websites das mesmas podem representar possíveis instrumentos que possibilitem o ensino-aprendizagem relacionado à informação para a comunidade acadêmica.

Tradicionalmente, a educação de usuários, como prática existente nas bibliotecas, é compreendida como um o esforço que envolve planejamento, execução e avaliação, não simplesmente ações isoladas, para proporcionar aos usuários maior entendimento e uso adequado dos recursos de informação disponíveis naquelas (CAMPELLO, 2009; BELLUZZO, 1989; BERNHARD, 2002; FJÄLLBRANT; STEVENSON, 1978; FLEMING, 1990; KUHLTHAU, 2004; MEWS, 1972; TIEFEL, 1995).

A literatura aponta que a educação de usuários sofreu alterações teórico-conceituais e pragmáticas, muito em função da evolução dos suportes informacionais, do avanço e da implantação das tecnologias digitais nas bibliotecas, como também a presença de perfis diferenciados de usuários. Concorda-se com o diagnóstico dado por Carvalho (2004, p. 20) quando expõe que as bibliotecas " [...] enfrentam a transição de estoques de documentos para a acessibilidade e disponibilização da informação e que por isso precisam rever e redesenhar ações, produtos e serviços.”. A partir desse entendimento, encontra-se uma inter-relação entre a prática da educação/formação dos usuários e os websites, que por meio de suas funções representam um instrumento que pode permitir ao indivíduo maior propriedade com relação

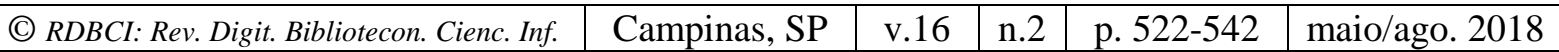


ao acesso, uso e comunicação da informação à sociedade, por conseguinte, potencializando o desenvolvimento da competência relacionada à informação para a construção de conhecimento e o aprendizado no decorrer de sua trajetória profissional e social.

O trabalho ora apresentado é o resultado da terceira de um total de três etapas de uma pesquisa mais ampla desenvolvida junto ao Programa de Pós-Graduação em Ciência da Informação da Escola de Ciência da Informação da Universidade Federal de Minas Gerais $(\mathrm{PPGCI} / \mathrm{ECI} / \mathrm{UFMG})^{1}$, na Linha de Pesquisa Informação, Cultura e Sociedade, pesquisa cujo objetivo principal intencionava "analisar a contribuição das ações e/ou atividades de educação de usuários - presenciais e/ou online — promovidas por bibliotecas universitárias brasileiras vinculadas às instituições federais de ensino superior, para o processo de formação de competências em informação de seus estudantes/usuários, visando à construção de sujeitos autônomos e conscientes na condução do processo de busca e uso da informação."

Sendo assim, para esta etapa da pesquisa buscou-se identificar nos websites das bibliotecas universitárias $^{2}$ a prática da educação/formação de usuários por meio de produtos e serviços que podem ser fomentados tanto em ambientes tradicionais como digitais/virtuais na perspectiva da promoção de competências em informação dos estudantes.

\section{WEBSITES}

A Web tornou-se um recurso essencial na interlocução da biblioteca com os usuários, pois, se não houver essa integração, mesmo que ocorra de forma gradual, corre-se o risco de a biblioteca desaparecer em função da falta de usuários (BAX, 1998).

As bibliotecas universitárias (BUs) podem utilizar-se dos recursos tecnológicos digitais de forma ampla, desde a gestão de recursos internos, perpassando pelo desenvolvimento de produtos/serviços de informação, comunicação e interação e colaboração com os usuários. Desse modo, ainda pode ser considerada válida a asserção de Cunha (2000, p. 75), quando

\footnotetext{
${ }^{1}$ A pesquisa "Da educação de usuários à construção de competência em informação no contexto das bibliotecas das universidades federais: um estudo a partir da Universidade Federal de Alagoas e Universidade Federal de Minas Gerais" foi aprovada em maio/2015 pelo Comitê de Ética em Pesquisa da Universidade Federal de Minas Gerais, Parecer n. 1.057.272/2015. O Comitê de Ética em Pesquisa da Universidade Federal de Alagoas aprovou a coparticipação desta instituição em outubro/2015. Ressalta-se que a primeira etapa da pesquisa foi realizada com 2.133 estudantes de graduação de todas as áreas do conhecimento inseridos nos cursos de graduação presenciais das duas universidades. Uma síntese da primeira etapa foi apresentada em 2016 no XVII Encontro Nacional de Pesquisa em Ciência da Informação (XVII ENANCIB). A segunda etapa da pesquisa teve a participação de 31 bibliotecários(as)/gestores(as) das bibliotecas universitárias, encontra-se em fase de compilação e será apresentada posteriormente. A pesquisa completa está disponível na Biblioteca de Teses e Dissertações - Universidade Federal de Minas Gerais.

${ }^{2}$ Ressalta-se que as análises apresentadas representam uma fotografia do momento no qual foi realizada a coleta de dados. Provavelmente, algumas das bibliotecas partícipes da pesquisa já se encontrem em outra realidade, pois após a coleta de dados não se realizou nenhum tipo de monitoramento.
} 
afirma que "[...] nos últimos 150 anos, as bibliotecas sempre acompanharam e venceram os novos paradigmas tecnológicos.", mesmo porque o autor considera que as BUs sempre fizeram uso dos mais variados recursos advindos das tecnologias da informação.

Nesse sentido, Merlo Vega (2007) sustenta que as bibliotecas podem ser classificadas em três níveis, conforme sua relação com a tecnologia digital: passiva, ativa e interativa. As bibliotecas passivas são compreendidas como aquelas que utilizam a tecnologia digital internamente no desenvolvimento de suas atividades, entretanto, sem oferecer serviços/produtos de informação aos seus usuários por meio da Web. São entendidas como ativas as que utilizam os recursos digitais e sistemas eletrônicos, não somente para suas atividades internas, como também no desenvolvimento de serviços e produtos em rede para seus usuários. Neste caso, incluem-se os serviços e produtos de comunicação, informação e referência; bibliotecas digitais e repositórios; e competência em informação (tutoriais). As bibliotecas interativas são para o autor aquelas que fazem uso participativo com relação a essas tecnologias, recebem e oferecem informações por meio de serviços digitais e eletrônicos. Tais bibliotecas concebem espaços digitais (interativos) para troca de informações e conhecimento com os usuários. Merlo Vega (2007) destaca que, por meio da Web social, a biblioteca pode ser utilizada como um instrumento tanto para oferecer novos serviços como inovar aqueles já existentes. Inclui-se, como exemplo, a formação dos usuários, isto é, podem propiciar a competência em informação (CoInfo) e, desse modo, o aprendizado ao longo da vida por meio de sistemas online (blogs, wiki) ou plataformas eletrônicas.

Amaral e Guimarães $(2002,2008)$ apresentam seis funções articuladas que podem ser executadas pelos websites das unidades de informação e denotam possíveis capacidades de manterem uma interação entre tais unidades e os usuários como instrumentos de prestação de serviços e disseminadores de informações. As autoras apresentam uma classificação para as funções dos websites, como: informacional - capacidade de apresentar ao usuário uma visão ampla da estrutura da unidade de informação e da instituição à qual a unidade encontra-se vinculada; promocional - capacidade para a promoção da unidade de informação e dos recursos informacionais; instrucional - capacidade do website de transmitir aos usuários formas de uso dos recursos de informação disponibilizados tanto no ambiente tradicional quanto aqueles oferecidos pelo próprio website; referencial - capacidade do website de servir como um sistema de referência ou ponto de acesso para outros recursos de informação excedendo ao ambiente tradicional; pesquisa - capacidade de disponibilizar uma variedade e quantidade de produtos e serviços online; e, por fim, a função comunicacional - capacidade de interação do website na disponibilização de instrumentos para permitir relacionamentos entre o usuário e a unidade de informação.

Ao se considerar tais funções, o website pode ser considerado um instrumento de comunicação ou mediação entre a biblioteca e o usuário (AMARAL; GUIMARÃES, 2002,

\begin{tabular}{l|l|l|l|l|l} 
(C) RDBCI: Rev. Digit. Bibliotecon. Cienc. Inf. & Campinas, SP & v.16 & n.2 & p. 522-542 & maio/ago. 2018
\end{tabular} 
2008), logo, o mesmo torna-se um instrumento de discurso, pois disponibiliza possíveis serviços, produtos, informações, documentos, tutoriais para os usuários, como também instrumentos/ferramentas tecnológicas utilizadas pelas bibliotecas para a promoção da formação dos usuários.

\section{TRILHA METODOLÓGICA}

Pesquisa classificada como exploratória, pois se pretendeu investigar "[...] temas e objetos com base em novas perspectivas e ampliar [ou mapear] estudos já existentes." (HERNÁNDEZ SAMPIERI; FERNÁNDEZ COLLADO; BAPTISTA LUCIO, 2006, p. 99), nesse caso, estabelecer uma ótica sobre os websites das BUs.

A análise de conteúdo (Web) é considerada por Uribe Tirado (2012) como um instrumento adequado para analisar os websites das bibliotecas inseridas em ambientes acadêmicos. Para Haas e Grams (1998) a análise de conteúdo permite examinar as páginas na Web e os links dispostos nas mesmas. Nessa perspectiva, torna-se possível localizar, identificar, organizar como também avaliar e classificar as informações contidas nos websites.

Estabeleceram-se para a pesquisa duas universidades: Universidade Federal de Alagoas (UFAL) e a Universidade Federal de Minas Gerais (UFMG), por meio da amostragem por acessibilidade. Tal amostragem é considerada nas pesquisas sociais, pois permite, com base nos princípios de Gil (2006), que se lance mão de elementos mais acessíveis e que ficam unicamente a julgamento/critério do pesquisador.

Para determinar o instrumento de coleta de dados, utilizou-se o suporte teóricometodológico tanto de Amaral (2008), Amaral e Guimarães (2002, 2008), como também de Bardin (2004). As primeiras autoras, por proporem em seus estudos uma classificação das funções dos websites, na qual se destaca a "instrucional", que se refere à capacidade que o site possui para instruir os sujeitos em relação aos recursos informacionais proporcionados pela biblioteca tanto no ambiente tradicional, como também através do website. Não há, conforme Amaral (2008), uma rigidez sobre os itens que compõem determinada função de um website, estes podem estar presentes em uma ou mais funções. Já Bardin, por fornecer elementos conceituais e operacionais que possibilitaram maior segurança na categorização dos elementos que se apresentavam nesses sites e que se coadunavam com o interesse desta pesquisa.

Tendo essa clareza, estabeleceram-se duas ações: i-) inventário - levantamento de todos os elementos que estão presentes no site - observando-se que apenas os elementos correspondentes aos possíveis instrumentos de promoção à educação/formação dos usuários fizeram parte dessa ação; ii-) classificação - distribuir os elementos de acordo com categorias

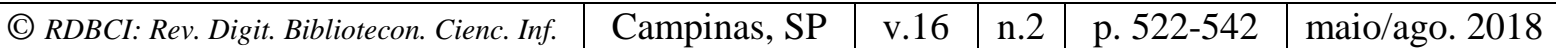


(pré)definidas. Categorização que consistiu em diferenciar, reagrupar e, posteriormente, associar os elementos ou dados em categorias estabelecidas (Quadro 1).

Quadro 1 - Função instrucional dos websites por categorias e elementos nas universidades investigadas - UFAL e UFMG

\begin{tabular}{|c|c|}
\hline \multicolumn{2}{|l|}{ Função Instrucional - websites } \\
\hline Categoria(s) & Elemento(s) \\
\hline $\begin{array}{l}\text { - Extensão do processo de busca - engloba a capacidade do site e da } \\
\text { biblioteca para disponibilizar e ampliar recursos de busca e } \\
\text { localização de fontes de informação, independentemente daqueles } \\
\text { disponibilizados pela biblioteca. }\end{array}$ & $\begin{array}{l}\text { - COMUT; } \\
\text { - Links para websites de } \\
\text { outras bibliotecas, } \\
\text { instituições e serviços de } \\
\text { informação; } \\
\text { - Publicações digitais; } \\
\text { - Especialistas em } \\
\text { determinado domínio do } \\
\text { conhecimento. }\end{array}$ \\
\hline $\begin{array}{l}\text { - Orientação/instrução - esclarecimentos geral e específico sobre } \\
\text { serviços e produtos de informação disponíveis tanto de forma } \\
\text { presencial como virtual/online. }\end{array}$ & $\begin{array}{l}\text { - Acesso físico ao acervo; } \\
\text { - Normalização; } \\
\text { - Pesquisa bibliográfica; } \\
\text { - Procedimentos e } \\
\text { regulamentos; } \\
\text { - Uso da biblioteca; } \\
\text { - Visitas. }\end{array}$ \\
\hline $\begin{array}{l}\text { - Rede e mídia social - estrutura que busca a inter-relação da } \\
\text { biblioteca com a comunidade acadêmica para o compartilhamento de } \\
\text { informações, conhecimento e comunicação. }\end{array}$ & $\begin{array}{l}\text { - Blogs, email, Facebook, } \\
\text { chats, Twitter e Whatsapp. }\end{array}$ \\
\hline $\begin{array}{l}\text { - Treinamento - estratégia utilizada pela biblioteca para possibilitar ao } \\
\text { sujeito maior conhecimento e autonomia no uso dos recursos de } \\
\text { informação disponíveis de forma presencial e virtual/online. }\end{array}$ & $\begin{array}{l}\text { - Catálogo online; } \\
\text { - Base de dados (BDTD, } \\
\text { Scielo, bases específicas a } \\
\text { cada área do conhecimento); } \\
\text { - Portal de Periódicos da } \\
\text { CAPES. }\end{array}$ \\
\hline $\begin{array}{l}\text { - Tutorial - ferramenta autoinstrucional disponibilizada por meio de } \\
\text { um programa de computador ou ainda um texto que possibilite o } \\
\text { processo de ensino/aprendizagem, expondo de forma detalhada como } \\
\text { utilizar os serviços e produtos informacionais. }\end{array}$ & $\begin{array}{l}\text { - Programas; } \\
\text { - Manuais; } \\
\text { - Guias. }\end{array}$ \\
\hline
\end{tabular}

Fonte: Dados da pesquisa, 2016. 
Com base nesse quadro, estruturou-se um formulário (Apêndice A), o qual permitiu categorizar os serviços direcionados à educação/formação dos usuários tanto para a UFAL como para a UFMG. A partir dos dados desse formulário procedeu-se a uma análise do mesmo, para verificar se os serviços representados eram potenciais no desenvolvimento de competências em informação nos usuários.

\section{ANÁLISE DOS SERVIÇOS DIRECIONADOS AOS USUÁRIOS - EDUCAÇÃO/FORMAÇÃO DE USUÁRIOS: WEBSITES}

Como parte intrínseca desta pesquisa, coletaram-se dados relacionados aos serviços e produtos disponibilizados nos websites das bibliotecas. Os dados levantados proporcionaram uma visão descritivo-exploratória dos potenciais indicativos à educação/formação de usuários, quer em ambientes tradicionais como digitais/virtuais, para possibilitar a promoção de competências em informação e que ofereceram subsídios para as análises.

Ressalta-se que o ato de coleta deteve-se em levantar exclusivamente os dados disponíveis e, desse modo, não houve propósito de verificar ou analisar atributos como: arquitetura da informação, design, mecanismos de navegação, funcionalidade dos links e configurações, entre outros, pois não se conformavam como objetivo desta investigação.

A presença da tecnologia digital em ambientes domésticos e profissionais, utilizada para acesso e recuperação da informação, causa afastamento dos espaços físicos tradicionais de acumulação da informação (BAX, 1998; CUNHA, 2010; DIB; LIMA, 2013; DIÓGENES, 2012). Logo, torna-se mais agravante a ausência de websites nas BUs, configurando-se como uma barreira no ambiente acadêmico, pois acarreta a indisponibilização de informações institucionais, como também da promoção dos recursos informacionais; a impossibilidade de uma relação de troca e mediação entre a biblioteca e o usuário (AMARAL, 2008; AMARAL; GUIMARÃES, 2002, 2008; SANTOS, 2012); a inviabilidade de acesso e uso, por parte da comunidade acadêmica, de vários recursos informacionais disponibilizados via Web, independentemente do tempo e do espaço (AMARAL, 2008) e, consequentemente, o inevitável distanciamento dos usuários das bibliotecas.

Independentemente se a biblioteca possui um website hospedado em servidor próprio ou se utiliza da unidade acadêmica ou administrativa, constatou-se que, das 35 bibliotecas partícipes desta pesquisa, 13 bibliotecas (37\%) não dispunham de websites no momento da investigação. Desse montante, 12 bibliotecas se encontram localizadas na UFAL e uma biblioteca, na UFMG.

A partir desse resultado, a pesquisa ficou restringida a 22 bibliotecas, sendo uma pertencente à UFAL - Biblioteca Central da UFAL (BC/UFAL), e 21 bibliotecas inseridas na UFMG - bibliotecas setoriais e a Biblioteca Central da UFMG (BC/UFMG).

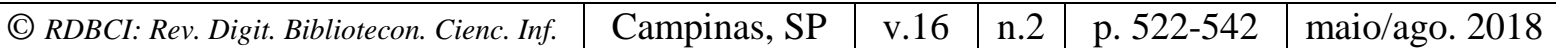


As cinco categorias de análise propostas, conforme apresentado no Quadro 1, representam ações ou atividades direcionadas à educação/formação dos usuários para possibilitar a construção de competências em informação.

\subsection{PRIMEIRA CATEGORIA: EXTENSÃO DO PROCESSO DE BUSCA}

Relaciona-se com a capacidade do site e da própria biblioteca para disponibilizar e ampliar os recursos de busca e localização de fontes de informação, independentemente daqueles disponibilizados no espaço físico da biblioteca. Um dos indicadores propostos pela Association of College and Research Libraries (2000) para a competência em informação considera que o estudante, para resolver suas necessidades de informação, identifique e diferencie recursos potenciais de informação nos mais diversos formatos e ambientes. Nesse sentido, serviços como o COMUT e acesso a outros recursos informacionais por meio de links para diversas fontes de informação (instituições, bibliotecas e materiais informacionais) permitem ao usuário ampliar seu processo de busca, desse modo, não limitando o acesso somente à informação disponível no espaço da biblioteca.

Na UFAL esse serviço foi constatado na única biblioteca que possuía site, a BC/UFAL, enquanto que na UFMG o índice desse serviço atingiu 95\% das bibliotecas.

Tais serviços proporcionados pelas bibliotecas possibilitam ao estudante reconhecer o valor e as fontes de informação em sua área do conhecimento e estabelecer um planejamento exequível para o desenvolvimento de suas pesquisas acadêmicas, considerando a quantidade, relevância, custo e tempo para obtenção e uso das fontes de informações. Nesse sentido, a divulgação realizada pela biblioteca tem sua importância, contudo somente a promoção tornase insuficiente, o usuário necessita compreender a funcionalidade dos serviços no contexto do processo de busca da informação para que possa, caso necessário, fazer o uso de tais serviços e produtos.

\subsection{SEGUNDA CATEGORIA: ORIENTAÇÃO/INSTRUÇÃO}

Assume importância ao estabelecer o elo entre a biblioteca, o usuário e a informação, uma vez que comporta ações que consistem no esclarecimento sobre o uso dos serviços e produtos de informação (BELLUZZO, 1989; FIGUEIREDO, 1991; FJÄLLBRANT; STEVENSON, 1978) que se encontram também no ambiente virtual/online.

A orientação/instrução representa um nível amplo e essencial, pois constitui, para muitos estudantes universitários, o primeiro contato com uma biblioteca e, desse modo, possibilita aos mesmos conhecer a estrutura, o funcionamento e os recursos de informação disponibilizados pela biblioteca (BERNHARD, 2002; DOWNARD, 1992; FIGUEIREDO, 1991). É a partir desse relacionamento inicial que se estabelece a fidelização com o usuário,

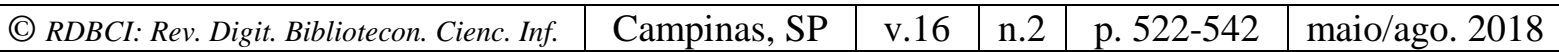


ao tempo em que esse começa a internalizar comportamentos relacionados ao processo de busca, acesso e uso da informação e dos recursos informacionais, pois um dos indicadores de competência em informação para os estudantes indicados pela Association of College and Research Libraries (2000) pressupõe o acesso e uso ético da informação por sujeitos que tenham noção das normas, leis, regulamentos e das devidas políticas institucionais.

A coleta realizada por meio dos websites constatou que a UFAL e a UFMG adotavam procedimentos com o objetivo de indicar ou esclarecer sobre os produtos e serviços oferecidos à comunidade acadêmica.

O website da BC/UFAL possibilitava acesso ao Guia do Usuário, com indicações básicas sobre normas e procedimentos e, até mesmo, direcionamento para a localização dos livros no acervo.

Na UFMG, com relação a procedimentos, normas e regulamentos, três (14\%) bibliotecas não disponibilizavam essas informações através do website. Tais informações podem ser transmitidas de outras formas aos usuários, por meio de folhetos, cartazes, guias impressos, visitas, pessoalmente, por email, entre outras. O Guia do Usuário ofertado pela UFMG, apesar de ser um instrumento genérico que divulga informações sobre os principais serviços e produtos oferecidos pelas bibliotecas, encontra-se disponível em formato eletrônico e era veiculado, aproximadamente, por oito (38\%) das bibliotecas.

Outro ponto a destacar são as visitas, consideradas como iniciativas por proporcionarem maior aproximação entre a biblioteca, o usuário e os materiais informacionais (BELLUZZO, 1989; CARVALHO, 2008; DUDZIAK; GABRIEL; VILELA, 2000; FIGUEIREDO, 1991; SILVA, 1995). Observou-se que na UFAL as visitas aconteciam mediante agendamento, e que no website veiculava-se um tour virtual na biblioteca. Constatou-se que 12 (57\%) das bibliotecas da UFMG explicitavam que ofereciam esse tipo de serviço, do mesmo modo que na UFAL, mediante agendamento. Nesse sentido, tal ação não estava inclusa como uma prática pelas bibliotecas e aconteciam somente em função de uma demanda.

Por outro lado, uma biblioteca da UFMG disponibilizava vídeo no website e essa mesma mídia era utilizada para que os usuários tivessem noções sobre como realizar pesquisas básicas no catálogo online. Ainda, no âmbito da UFMG, destaca-se que a orientação era estruturada em formato de aulas em duas bibliotecas. Uma delas, no início do semestre, para pesquisa e normalização para construção de trabalhos acadêmicos. Enquanto que a outra oferecia orientação em formato de aula expositiva, contudo, a mesma deveria ser realizada por meio de solicitação de algum docente, desse modo, indica a descaracterização de uma ação permanente da biblioteca. Uma terceira biblioteca disponibilizava apresentação em formato eletrônico (Power Point) disponível no site para os calouros e demais usuários que tivessem interesse em acessá-la. 
Havia prevalência das visitas e orientações como ações genéricas. Eram operacionalizadas no ambiente tradicional e aconteciam muito em função do interesse dos usuários, assim os websites tornavam-se um instrumento que atuava na dimensão da divulgação de tais ações ou atividades. Não foi possível detectar ações colaborativas para a aprendizagem entre as bibliotecas investigadas e as unidades acadêmicas no ambiente virtual. 4.3 TERCEIRA CATEGORIA: REDE E MÍDIA SOCIAL

Abrange até mesmo aquelas bibliotecas que não detêm website. Na UFAL, por meio do website da BC/UFAL, foi possível detectar que sete (54\%) das 13 BUs não mantinham diretamente esse canal de comunicação com a comunidade no momento da coleta de dados. Na UFMG o índice de presença de rede e mídia social atingia a totalidade das bibliotecas, 22 (100\%). Esse dado mostra-se relevante, na medida em que permite às bibliotecas maior dinâmica de comunicação e relacionamento com os usuários. Os dados corroboram com a pesquisa de Santos (2012), que detectou aumento de iniciativas através da Web social para fortalecer a aproximação e interlocução entre a biblioteca e os usuários, todavia, a autora alerta para a falta de uso pleno das ferramentas de comunicação como potencial recurso para acesso e uso da informação.

Os resultados desta categoria indicam que a rede e a mídia social funcionavam como instrumentos que possibilitavam fluxos interativos sociais, resultando na possibilidade de criação de conhecimento e aprendizado, como também para fomentar a participação, mobilização e diálogos com os usuários ao mesmo tempo em que potencializavam as ações e as práticas das bibliotecas. Considera-se, então, uma circunstância favorável às bibliotecas investigadas o investimento em recursos de participação coletiva em torno dos temas em que se inserem as práticas informacionais. Para a Association of College and Research Libraries (2012) a tecnologia continuará a exercer influência nas BUs, desse modo, o uso intensivo através das redes e mídias sociais configura-se como tendência. Assim, como prevê a própria Association of College and Research Libraries (2000), a participação em fóruns de comunicação eletrônica (email e sala de bate-papo) é considerada um meio que o estudante com competência em informação adota para validar tanto o seu entendimento como sua interpretação das informações, utilizando-se da interação com outros atores sociais (professores, especialistas e outros profissionais).

As ferramentas de comunicação representam verdadeiras aliadas para as bibliotecas perante os novos perfis dos usuários, possivelmente mais conectados às redes sociais (SOUSA, 2009).

Assim a própria classificação para os programas de educação/formação direcionados aos usuários da biblioteca de forma indireta, estabelecida por Belluzzo (1989), Dias e Pires 
(2004), corresponde ao uso da tecnologia digital, caracterizando-se pela interação homemcomputador e não somente de forma presencial.

\subsection{QUARTA CATEGORIA: TREINAMENTO}

O treinamento pode ser entendido como processo ou ação ininterrupta de educação (FIGUEIREDO, 1991) ou ainda estratégias para desenvolver habilidades nos usuários (BELLUZZO, 1989), consequentemente, associa-se ao aprendizado em relação à informação (CAREGNATO, 2000), e ao uso dos recursos disponíveis pelas tecnologias digitais (DIAS; PIRES, 2004). Wilson (1979) ratifica que o treinamento beneficia diversos segmentos sociais ao possibilitar habilidades vinculadas à informação. $O$ treinamento pode ser também entendido como uma atividade de inovação, quando for necessário para implantação de um produto ou processo novo ou aprimorado. (ORGANIZAÇÃO..., 2005).

O levantamento realizado nos websites das bibliotecas investigadas indica a presença de treinamento na BC/UFAL direcionado à recuperação da informação em meio eletrônico.

Na UFMG, 12 (57\%) das bibliotecas explicitavam a existência de treinamento, em sete (33\%) não havia nenhuma referência quanto à disponibilização de treinamentos para a comunidade acadêmica e, no ato da coleta de dados, em duas (10\%) BUs os websites encontravam-se fora do ar ou em manutenção e uma biblioteca não disponibilizava website. Das 12 bibliotecas que apresentavam esse tipo de ação, verificou-se que: o treinamento encontrava-se relacionado, principalmente, ao Portal de Periódicos da CAPES, seguido de outros tipos de treinamento, independentemente desse Portal, como busca e uso da coleção do acervo, e bases de dados em áreas específicas. Também foi possível constatar que, dentre essas bibliotecas, o treinamento apareceu referenciado por meio do regulamento interno ou, ainda, sem uma devida especificação.

As pesquisas realizadas com foco em competência em informação no ensino superior revelam que o treinamento torna possível tal competência, pois possibilita aos usuários maior apreensão nas estratégias de busca, conforme evidenciou Pereira (2011). Na pesquisa de Melo (2008), a ausência do treinamento se revela como dano ao desenvolvimento de habilidades relacionadas à informação para os discentes e, inclusive, oportunidades para que o uso das ferramentas de comunicação se torne uma nova opção para os tradicionais treinamentos em função de perfis diferenciados de usuários.

Contudo, cabe esclarecer que, na universidade, os sujeitos possuem múltiplos comportamentos e atitudes frente às tecnologias digitais. Com essa amplitude de perfis, o treinamento se faz necessário à comunidade acadêmica, potencializando a um grupo considerado como nativos digitais maiores conhecimentos em relação às fontes de informação especializadas e específicas em sua área e, também, para aqueles que desconhecem o sistema simbólico das tecnologias digitais e os produtos e serviços

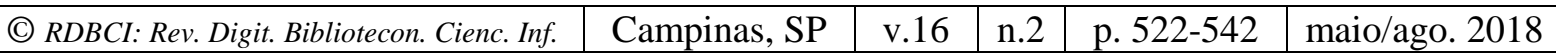


informacionais; provavelmente, recaia sobre esse segundo grupo maior demanda quanto à necessidade de capacitação em ambientes digitais, pois o treinamento no contexto universitário revela ações para o aprendizado das práticas de uso dos recursos informacionais, principalmente, diante da presença dos recursos eletrônicos.

Não se pode desprezar o desenvolvimento de tutoriais online que, conforme Hatschbach (2002), são tecnologias pedagógicas institucionais que permitem treinamento virtual e, ainda conforme a autora, possibilitam a autonomia dos estudantes.

\subsection{QUINTA CATEGORIA: TUTORIAL}

Nesta categoria, o tutorial como instrumento ou ferramenta de ensino/aprendizagem, permite a autoaprendizagem, para que o estudante, sem auxílio de outrem, obtenha diretrizes/instruções para acessar determinados serviços e/ou produtos disponibilizados pelas BUs, independentemente da localização física ou geográfica dos indivíduos e dos documentos.

Em três (14\%) das bibliotecas da UFMG os websites estavam em manutenção/construção durante o período de coleta de dados. Constatou-se a existência de link específico intitulado tutorial na arquitetura do website de quatro (19\%) das bibliotecas da UFMG. Porém deve-se ressaltar que 14 (67\%) das bibliotecas da UFMG e a BC/UFAL não possuíam um link determinado que direcionasse a um tutorial.

Verificou-se, quando possível, que as informações nesta categoria - tutorial - se encontravam de forma díspar nos websites e os tutoriais vinculavam-se aos próprios provedores de informação, quer fossem nacionais ou internacionais. O tutorial, nesse aspecto, configura-se como um instrumento único dos produtores para um número indefinido de usuários reais e potenciais. Desse modo, nem sempre tais tutoriais traduzem as dificuldades dos estudantes locais em relação à busca e ao acesso da informação em suas áreas de conhecimento. De certa forma, isso chama a atenção como um desafio para as bibliotecas e bibliotecários(as), pois as pesquisas de Hatschbach (2002) e Piccolo (2009) legitimam a participação dos(as) bibliotecários(as) e a cooperação de outros(as) profissionais no desenvolvimento e efetivação de tutorias nas BUs.

A participação dos(as) bibliotecários(as) na elaboração de tutoriais torna-se necessária e justificável, na medida em que são esses(as) profissionais que possuem a responsabilidade de capacitar os sujeitos a utilizarem a biblioteca e os recursos informacionais (CAMPELLO, 2009).

Loerstcher e Woolls (2005) aduzem que o uso da tecnologia da informação na arquitetura de tutoriais e folhetos eletrônicos é uma forma de envolvimento da biblioteca e

\begin{tabular}{|c|c|c|c|c|c|}
\hline (C) RDBCI: Rev. Digit. Bibliotecon. Cienc. Inf. & Campinas, SP & v.16 & n.2 & & maio/a o 2018 \\
\hline
\end{tabular}


dos(as) bibliotecários(as) no desenvolvimento desses produtos/serviços para os usuários. Ainda Hatschbach (2002) aponta os tutoriais como uma possibilidade para que os estudantes, além de adquirirem autonomia, tornem-se responsáveis e aprendizes de tecnologias tanto para sua formação acadêmica como profissional. Os dados demonstram que um total de sete (32\%) bibliotecas entre a UFAL e UFMG desenvolveram guias/manuais de normalização, por meio dos(as) bibliotecários(as) e até mesmo pelos docentes vinculados ao curso de Biblioteconomia nessas instituições, possibilitando à comunidade acadêmica o passo a passo para garantir a padronização de documentos, veracidade das fontes de informações, proteção dos direitos autorais e melhoria na comunicação científica; tais aspectos são decisivos na formação dos estudantes para a competência em informação, pois envolvem questões éticas, legais e sociais no uso e comunicação da informação.

Na UFMG detectou-se também que em uma biblioteca houve a cooperação entre bibliotecários(as) e outro profissional de outra área no desenvolvimento de uma ferramenta para a comunidade acadêmica - um gerenciador bibliográfico.

A realidade constatada durante o processo de coleta de dados apresenta um resultado que se projeta como desafio e também oportunidade para as bibliotecas, o desenvolvimento de tutoriais online para treinamento virtual, uma vez que não foi possível estabelecer a existência desses.

\section{CONSIDERAÇÕES FINAIS}

Os websites das BUs investigadas cumpriam, até o momento da coleta de dados, duas funções principais: informacional e referencial dos seus serviços e produtos, havendo um maior direcionamento para as ações presenciais em detrimento das virtuais/online. Não foi possível identificar, por meio dos websites, parcerias entre as bibliotecas e no interior dessas com suas unidades acadêmicas para o desenvolvimento de um programa ou até mesmo de ações para a competência em informação. Termos como "orientação", "instrução" e "treinamento" eram utilizados de forma genérica indicando ações isoladas ou pontuais, muito em função de uma demanda; tais ações configuram-se como as únicas utilizadas pelas BUs para proporcionar à comunidade acadêmica maior aproximação com os recursos informacionais e, a partir daí, provocar mudança de comportamento (acadêmica, pessoal e profissional) em relação a esses recursos.

Também não foi possível constatar o estabelecimento de um programa virtual para a formação de competências, desse modo, indicando que as bibliotecas não utilizavam a potencialidade dos recursos tecnológicos, cabendo ações tímidas em relação ao processo de aprendizagem envolvendo a informação e, consequentemente, a ausência de articulação entre a biblioteca, os docentes, os estudantes e as unidades acadêmicas/administrativas para a promoção de competências em informação. 
As análises dos websites apresentadas convergem para conformar, segundo a classificação proposta por Merlo Vega (2007), que as bibliotecas das duas instituições encontravam-se classificadas, conforme sua relação com a tecnologia, em distintos processos de transição.

Considerando o ponto de vista de uso da tecnologia digital para a promoção das ações de educação/formação de usuário para fomentar a competência em informação, a UFAL encontrava-se do nível passivo para o ativo, pois somente a BC/UFAL possuía website até o momento da coleta, impactando desse modo o fornecimento de serviços/produtos de informação aos seus usuários por meio da Web. Incidindo maior responsabilidade sobre tal biblioteca para promover acesso aos serviços e produtos à comunidade acadêmica, ao mesmo tempo em que ela assume visibilidade para suas ações e se apresenta como um referencial para as outras bibliotecas setoriais dessa instituição.

No caso da UFMG, a transição se dava nos três níveis, do passivo para ativo e desse caminhando para o interativo. Essa transição não pode ser considerada de forma genérica, pois as bibliotecas dessa instituição atendem áreas específicas do conhecimento e, consequentemente, não apresentam o mesmo nível de recursos e alinhamento entre si em relação à oferta de serviços e produtos em informação pela Web.

Todavia, há inúmeros desafios práticos a serem integrados pelas bibliotecas da UFAL e da UFMG em suas ações para que a formação de usuários atinja o nível interativo, como forma de instrumentalizar os usuários por meio de sistemas online ou de plataformas eletrônicas para que, desse modo, possam formar competência em informação.

Entre os desafios a serem enfrentados destaca-se uma série de atitudes, atividades e recursos que as bibliotecas e os(as) bibliotecários(as) devem empreender, e entre esses desafios encontram-se aqueles apresentados nos estudos de Belluzzo (2010), Ducas e Michaud-Oystryk (2003) e Hernandez-Hernandez (2010). Pode-se então destacar aqueles que são factíveis no âmbito das BUs investigadas nesta pesquisa, como: a inserção da competência em informação como parte das estratégias da universidade; a competência deve ambranger todas as graduações; a biblioteca deve receber apoio instuticional e possuir tempo para desenvolver programas e materiais de formação para a comunidade acadêmica, inicialmente, para as graduações; a biblioteca necessita planejar atividades de avaliação da aprendizagem, como também elaborar ações de marketing; desenvolver e/ou aperfeiçoar os recursos tecnológicos para a implementação de programas online; fornecer novos e melhores serviços de informação competitivos; integrar e mobilizar bibliotecários(as), docentes e outros profissionais da universidade para desenvolverem em parceria instrumentos direcionados à competências em informação nos estudantes; maior desempenho por parte dos(as) bibliotecários(as) para atuarem no campo do ensino relacionado à informação; e a

\begin{tabular}{|c|c|c|c|c|c|}
\hline (C) RDBCI: Rev. Digit. Bibliotecon. Cienc. Inf. & Campinas, SP & v. 16 & n. 2 & o. 522-542 & \\
\hline
\end{tabular}


participação do(a) bibliotecário(a) em projetos de pesquisas junto ao corpo docente das universidades.

\section{REFERÊNCIAS}

ASSOCIATION OF COLLEGE AND RESEARCH LIBRARIES. Information literacy competency standards for higher education. Chicago: ALA, 2000. Disponível em: <http://www.ala.org/acrl/sites/ala.org.acrl/files/content/standards/standards.pdf>. Acesso em: $21 \mathrm{dez} .2015$.

ASSOCIATION OF COLLEGE AND RESEARCH LIBRARIES. 2012 top ten trends in academic libraries: A review of the trends and issues affecting academic libraries in higher education. College \& Research Libraries New, [S.1.], v. 73, n. 6, p. 311-320, June 2012. Disponível em: <http://crln.acrl.org/content/73/6/311.full>. Acesso em: 10 jun. 2016.

AMARAL, Sueli Angélica do. Desempenho das funções dos websites de unidades de informação como ferramenta de marketing para planejamento e gestão. In: FUJITA, M. S. L.; MARTELETO, R. M.; LARA, M. L. G. A dimensão epistemológica da Ciência da Informação e suas interfaces técnicas, políticas e institucionais nos processos de produção, acesso e disseminação da informação. São Paulo: Cultura Acadêmica, 2008. p. 135-154.

AMARAL, Sueli Angélica do; GUIMARÃES, Tatiara Paranhos. Sites das bibliotecas universitárias brasileiras: estudo das funções desempenhadas. In: SEMINARIO NACIONAL DE BIBLIOTECAS UNIVERSITARIAS, 12., 2002, Recife, Anais... Recife: UFPE, 2002. 1 CD-ROM.

AMARAL, Sueli Angélica do; GUIMARÃES, Tatiara Paranhos. Websites de unidades de informação como ferramentas de comunicação com seus públicos . Encontros Bibli, Florianópolis, v. 13, n. 26, p. 59-71, $2^{\circ}$ sem. 2008. Disponível em: <https://periodicos.ufsc.br/index.php/eb/article/view/1518-2924.2008v13n26p147/6642>. Acesso em: 10 jun. 2016.

BARDIN, Laurence. Análise de conteúdo. Lisboa: Edições 70, 2004.

BAX, Marcello Peixoto. As bibliotecas na Web e vice-versa. Perspectivas em Ciência da Informação, Belo Horizonte, v.3, n.1, p. 5-20, jan./jun. 1998. Disponível em: $<$ http://portaldeperiodicos.eci.ufmg.br/index.php/pci/article/viewFile/14/375>. Acesso em: 3 jan. 2016.

BELLUZZO, Regina Célia Baptista. Educação de Usuários de Bibliotecas Universitárias: da conceituação e sistematização ao estabelecimento de diretrizes. 1989. 107 f. Dissertação (Mestrado em Ciências da Comunicação) - Escola de Comunicações e Artes, Universidade de São Paulo, 1989. 
BELLUZZO, Regina Célia Baptista. Competências e novas condutas de gestão: diferenciais de bibliotecas e sistemas de informação. In: VALENTIM, Marta Lígia Pomim (Org.). Ambientes e fluxos de informação. São Paulo: Cultura Acadêmica, 2010. p. 23-54.

BELLUZZO, Regina Célia Baptista; FERES, Glória Georges. Competência em informação, redes de conhecimento e as metas educativas para 2021: reflexões e inter-relações. In: BELLUZZO, Regina Célia Baptista; FERES, Glória Georges; VALENTIM, Marta Lígia Pomim (Org.). Redes de conhecimento e competência em informação: interfaces da gestão, mediação e uso da informação. Rio de Janeiro: Interciência, 2015. p. 1-35.

BERNHARD, Paulette. La formación en el uso de la información: una ventaja en la enseñanza superior. Situación actual. Anales de Documentación, [Murcia], v. 5, p. 409-435, enero 2002. Disponível em: <http://revistas.um.es/analesdoc/article/view/2271/2261>. Acesso em: 12 dez. 2015.

CAMPELLO, Bernadete Santos. Letramento informacional no Brasil: práticas educativas de bibliotecários em escolas de ensino básico. 2009. 208 f. Tese (Doutorado em Ciência da Informação) - Escola de Ciência da Informação, Universidade Federal de Minas, Belo Horizonte. 2009.

CAREGNATO, Sonia Elisa. O desenvolvimento de habilidades informacionais: o papel das bibliotecas universitárias no contexto da informação digital em rede. Revista de

Biblioteconomia \& Comunicação, Porto Alegre, v. 8, p. 47-55, jan./dez. 2000.

CARVALHO, Fernanda Cordeiro de. Educação e estudos de usuários em bibliotecas universitárias brasileiras: abordagem centrada nas competências em informação. 2008. 145 f. Dissertação (Mestrado em Ciência da Informação) - Faculdade de Economia, Administração, Contabilidade e Ciência da Informação e Documentação, Universidade de Brasília, 2008.

CARVALHO, Isabel Cristina Louzada. A socialização do conhecimento no espaço das bibliotecas universitárias. Niterói: Intertexto, 2004.

CUNHA, Murilo Bastos da. Construindo o futuro: a biblioteca universitária brasileira em 2010. Ciência da Informação, Brasília, v. 29, n. 1, p. 71-89, jan./abr. 2000. Disponível em <http://revista.ibict.br/ciinf/index.php/ciinf/article/viewArticle/269>. Acesso em: 2 mar. 2016.

CUNHA, Murilo Bastos da. A biblioteca universitária na encruzilhada. DataGramaZeroRevista de Ciência da Informação, [Rio de Janeiro], v. 11, n. 6 , dez. 2010.

Disponível em: <http://www.dgz.org.br/dez10/art_07.htm>. Acesso em: 2 mar. 2016.

DIAS, Maria Matilde Kronka; PIRES, Daniela. Usos e usuários da informação. São Carlos: EdUFSCAR, 2004.

DIB, Simone Faury; LIMA, Clóvis Ricardo Montenegro de. Administração discursiva: uma nova perspectiva para as bibliotecas universitárias brasileiras. Informação@Profissões,

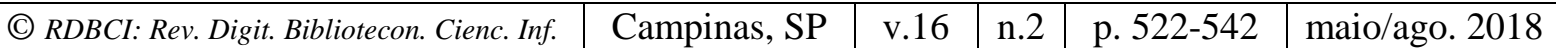


Londrina, v. 2, n. 2, p. 92-118, 2013. Disponível em: <www.uel.br/revistas/infoprof/>. Acesso em: 4 jun. 2016.

DIÓGENES, Fabiene Castelo Branco. Os novos papéis da biblioteca universitária brasileira. 2012. 444 f. Tese (Doutorado em Ciência da Informação) - Faculdade de Ciência da Informação, Universidade de Brasília, 2012. Disponível em:

$<$ http://repositorio.unb.br/bitstream/10482/12305/1/2012_FabieneCasteloBrancoDiogenes.pd f>. Acesso em: 10 dez. 2016.

DOWNARD, Karen. User education in academic libraries. Library Management, [S.1.], v. 13, n. 3, p. 29-38, 1992.

DUCAS, Ada M.; MICHAUD-OYSTRYK, Nicole. Toward a new enterprise: Capitalizing on the faculty librarian partnership. College and Research Libraries, Chicago, v. 64, n.1, p. 5573, 2003. Disponível em: <http://crl.acrl.org/content/64/1/55.full.pdf+html>. Acesso em: 16 jun. 2016.

DUDZIAK, Elisabeth Adriana; GABRIEL, Maria Aparecida; VILLELA, Maria Cristina Olaio. A educação de usuários de bibliotecas universitárias frente à sociedade do conhecimento e sua inserção nos novos paradigmas educacionais. In: SEMINÁRIO NACIONAL DE BIBLIOTECAS UNIVERSITÁRIAS, 11., 2000, Florianópolis: UFSC, 2000, p.1-19.

FIGUEIREDO, Nice Menezes de. Metodologias para a promoção do uso da informação: técnicas aplicadas particularmente em bibliotecas universitárias e especializadas. São Paulo: Nobel, 1991.

FJÄLLBRANT, Nancy; STEVENSON, Malcolm. User education in libraries. London: Clive Bingley, 1978.

FLEMING, Hugh. User education in academic libraries. London: Library Association, 1990.

GIL, Antonio Carlos. Métodos e técnicas de pesquisa social. 5. ed. São Paulo: Atlas, 2006.

GOMES, Marcos Aurélio. Da educação de usuários à construção de competência em informação no contexto das bibliotecas das universidades federais: um estudo a partir da Universidade Federal de Alagoas e Universidade Federal de Minas Gerais. 2016. Tese (Doutorado em Ciência da Informação) - Escola de Ciência da Informação, Universidade Federal de Minas Gerais, Belo Horizonte, 2016.

HAAS, Stephanie W.; GRAMS, Erika S. Page and link classifications: Connecting diverse resources. In: WITTEN, Ian H.; AKSCYN, Rob M.; SHIPMAN, Frank M. (Eds.),

Proceedings of Digital Libraries'98 - Third ACM Conference on Digital Libraries, 1998, Pittsburgh. New York: Association for Computing Machinery, 1998, p. 99-107. 
HATSCHBACH, Maria Helena de Lima. Information Literacy: aspectos conceituais e iniciativas em ambiente digital para o estudante de nível superior. 2002. 108 f. Dissertação (Mestrado em Ciência da Informação) - Escola de Comunicação, Universidade Federal do Rio de Janeiro, Rio de Janeiro. 2002.

HERNÁNDEZ HERNÁNDEZ, Carmen Julia. Un plan de formación en competencias de información a través de aulas virtuales: análisis de una experiencia con alumnado universitario. Revista de Universidad y Sociedad del Conocimiento, Barcelona, v. 7, n. 2, p. 50-61, jul. 2016.

HERNÁNDEZ SAMPIERI, Roberto; FERNÁNDEZ COLLADO, Carlos; BAPTISTA LUCIO, María del Pilar. Metodologia da pesquisa. 3. ed. São Paulo: McGraw Hill, 2006.

KUHLTHAU, Carol Collier. Seeking meaning: a process approach to library and information services. 2nd. ed. Westport: Libraries Unlimited, 2004.

LEITE, Cecília. et al. Cenário e perspectiva da produção científica sobre competência em informação (coinfo) no Brasil: estudo da produção no âmbito da ANCIB.

Informação \& Sociedade: Estudos, João Pessoa, v.26, n.3, p. 151-168, set./dez. 2016.

LOERSTCHER, David V.; WOOLLS, Blanche. Competência em informação: ajudando bibliotecários a aplicar a pesquisa no ensino da habilitação básica em obtenção de informação pelos usuários - a importância da interface humana. In: Passos, Rosemary; Santos, Gildenir Carolino (Org.). Competência e habilidades em informação na sociedade da aprendizagem. 2.ed. Bauru: Kairós, 2005. p. 55-66.

MELO, Ana Virgínia Chaves de. Análise do desenvolvimento dos estágios de competência informacional em estudantes do Curso de Graduação em Biblioteconomia da Universidade Federal da Paraíba - UFPB. 2008. 451 f. Dissertação (Mestrado em Ciência da Informação) - Centro de Ciências Sociais Aplicadas,Universidade Federal da Paraíba, João Pessoa, 2008. Disponível em:

<http://rei.biblioteca.ufpb.br/jspui/handle/123456789/204>. Acesso em: 8 jan. 2016.

MERLO VEGA, José Antonio. Las tecnologías de la participación en las bibliotecas. Educación y Biblioteca, [Salamanca], v.19, n. 161, sept./oct. 2007. Disponível em: <http://eprints.rclis.org/10558/1/tecnoparti.pdf>. Acesso em: 2 abr. 2016.

MEWS, Hazel. Reader instruction in colleges and universities: Teaching the use of the library. London: Bingley, 1972.

ORGANIZAÇÃO PARA COOPERAÇÃO E DESENVOLVIMENTO ECONÔMICO.

Manual de Oslo: diretrizes para coleta e interpretação de dados sobre inovação. 3. ed. Paris: OCDE, 2005. Tradução de: The Measurement of Scientific and Technological Activities Proposed Guidelines for Collecting and Interpreting Technological Innovation Data: Oslo Manual.

Disponível em: <http://www.finep.gov.br/images/a-finep/biblioteca/manual_de_oslo.pdf.>. Acesso em: 10 maio 2016. 
PEREIRA, Fernando Antônio de Sousa. O desenvolvimento da competência informacional para o pensamento estratégico: uma experiência no ensino da administração de empresas através da simulação empresarial competitiva. 2011. 198 f. Dissertação (Mestrado em Ciência da Informação) - Instituto em Ciência da Informação, Universidade Federal da Bahia, Salvador, 2011. Disponível em:

<https://repositorio.ufba.br/ri/bitstream/ri/7842/1/Disserta\%c3\%a7\%c3\%a3o\%20Final.pdf>. Acesso em: 23 dez. 2015.

PÍCCOLO, Homero Luiz. Tutorial dotado de inteligência para orientação de alunos novatos em uma biblioteca universitária: o caso da Biblioteca da Universidade de Brasília. 2006.184 f. Tese (Doutorado em Ciência da Informação) - Faculdade de Economia, Administração, Contabilidade e Ciência da Informação e Documentação Universidade de Brasília, Brasília, 2006. Disponível em:

<http://repositorio.unb.br/handle/10482/5039?mode=full>. Acesso em: 14 fev. 2016.

SANTOS, Raquel do Rosário. Espaço virtual e a comunicação com os usuários para a mediação da informação: utilização pelas bibliotecas das universidades federais e estaduais brasileiras. 2012. 248 f. Dissertação (Mestrado) - Instituto de Ciência da Informação, Universidade Federal da Bahia,. 2012. Disponível em:

<http://www.repositorio.ufba.br:8080/ri/handle/ri/7833>. Acesso em: 20 dez. 2015.

SILVA, Maria Neves de Oliveira e. Educação de usuários: um levantamento de práticas brasileiras em bibliotecas universitárias. 1995. 111 f. Dissertação (mestrado) - Faculdade de Estudos Sociais Aplicados, Universidade de Brasília, 1995.

SOUSA, Margarida Maria de. A biblioteca universitária como ambiente de aprendizagem no ensino superior. 2009. 90 f. Dissertação (Mestrado em Ciência da Informação) - Escola de Comunicação e Artes, Universidade de São Paulo, 2009. Disponível em: <file:///C:/Users/Marcos/Downloads/Margarida_M_Sousa_DISSERT.pdf>. Acesso em: 11 fev. 2016.

TIEFEL, Virginia M. Library user education: examining its past, projecting Its Future. Library Trends, Illinois, v. 44, n. 2, p. 318-38, Fall. 1995. Disponível em: <https://www.ideals.illinois.edu/bitstream/handle/2142/8026/librarytrendsv44i2h_opt.pdf?se quence=1>. Acesso em: 11 mar. 2016.

URIBE TIRADO, Alejandro. La alfabetización informacional en las bibliotecas universitarias de Brasil: visualización de los niveles de incorporación desde la información publicada en sus sitios Web. Perspectivas em Ciência da Informação, Belo Horizonte, v.17, n.1, p.134-152, jan./mar. 2012. Disponível em:

<http://portaldeperiodicos.eci.ufmg.br/index.php/pci/article/view/1303/993>.

Acesso em: 16 maio 2016.

WILSON, Thomas Daniel. Guidelines for developing and implementing a national plan for training and education in information use. Paris: Unesco, 1979. 


\section{APÊNDICE A}

Exemplo do Formulário utilizado na coleta de dados nos websites das universidades

\begin{tabular}{|c|c|c|c|c|c|c|c|c|c|c|c|c|c|c|}
\hline \multirow{2}{*}{$\begin{array}{c}\text { FUNÇÃO INSTRUCIONAL - } \\
\text { WEBSITES }\end{array}$} & \multicolumn{14}{|c|}{ UNIVERSIDADE XYZ } \\
\hline & B1 & B2 & B3 & B4 & B5 & B6 & B7 & B8 & B9 & B10 & B11 & B12 & B13 & B14 \\
\hline WEBSITES - BIBLIOTECAS & - & - & - & - & - & - & - & - & - & - & - & - & - & - \\
\hline CATEGORIAS & B1 & B2 & B3 & B4 & B5 & B6 & B7 & B8 & B9 & B10 & B11 & B12 & B13 & B14 \\
\hline EXTENSÃO DO PROCESSO DE BUSCA & - & - & - & - & - & - & - & - & - & - & - & - & - & - \\
\hline ORIENTAÇÃO/INSTRUÇÃOO & - & • & - & - & - & - & • & - & - & - & - & ND & - & - \\
\hline $\begin{array}{l}\text { REDES/MÍDIAS SOCIAIS (blogs, email, } \\
\text { Facebook, chats, Twitter e Whatsapp) }\end{array}$ & - & - & - & • & $\bullet$ & • & • & - & - & - & - & - & - & - \\
\hline TREINAMENTO & ND & - & - & - & - & - & - & - & - & - & - & ND & - & ND \\
\hline TUTORIAL (links) & - & - & - & - & - & ND & - & - & - & - & - & - & ND & ND \\
\hline
\end{tabular}

Legenda: B - Bibliotecas

ND - dado não disponível

- dado localizado
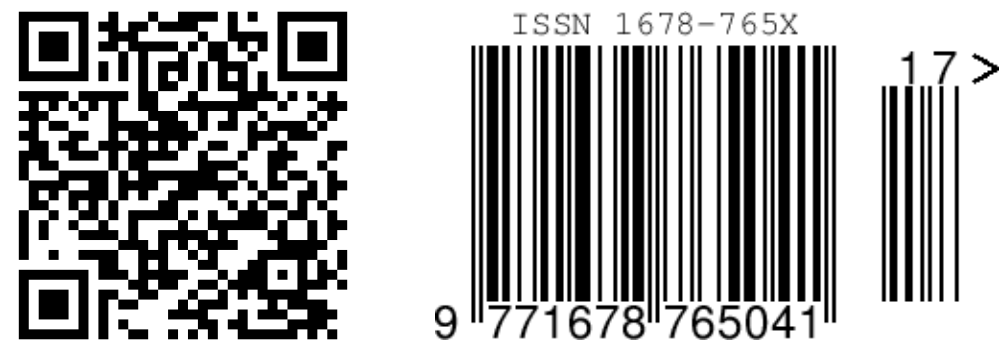